This document is the accepted manuscript version of the following article:

Boch, S., Martins, A., Sim-Sim, M., \& Bergamini, A. (2021). Effects of elevation and disturbances on the associations between the diversities of bryophyte and macrolichen functional-taxonomic groups on Madeira Island. Bryologist, 124(2), 178-190. https://doi.org/10.1639/0007-2745-124.2.178

The Bryologist 124 (2021) - Accepted version

\title{
Effects of elevation and disturbances on the associations between the diversities of bryophyte and macrolichen functional-taxonomic groups on
}

\section{Madeira Island}

Steffen Boch ${ }^{1,4}$, Anabela Martins ${ }^{2}$, Manuela Sim-Sim ${ }^{2,3}$ and Ariel Bergamini ${ }^{1}$

${ }^{1}$ WSL Swiss Federal Institute for Forest, Snow and Landscape Research, Birmensdorf, Switzerland; ${ }^{2}$ cE3c-Centre for Ecology, Evolution and Environmental Changes, Natural History and Systematics (NHS) Research Group / MUHNAC - Museu Nacional de História Natural e da Ciência, Universidade de Lisboa, Lisboa, Portugal; ${ }^{3}$ cE3c, Centre for Ecology, Evolution and Environmental Changes, Universidade de Lisboa, Faculdade de Ciencias, Lisboa, Portugal

ABSTRACT. Biodiversity varies with elevation and is affected by disturbances. However, little is known about how the associations between the diversities of different bryophyte and macrolichen functional-taxonomic groups are altered along elevational gradients and by disturbances. Knowledge on the associations between these functional-taxonomic groups might be of importance in practical conservation biology, as identifying indicator taxa which are easy to monitor could be useful in estimating a wider biodiversity. We sampled the

\footnotetext{
${ }^{4}$ Corresponding author's e-mail: steffen.boch@wsl.ch Coauthors Sim-Sim and Bergamini contributed equally to this work and share the last authorship. DOI: $10.1639 / 0007-2745-124.2 . x x x$
} 
species richness of bryophytes and macrolichens in 92 plots distributed in disturbed and undisturbed stands along elevational gradients in the laurel forest of Madeira. We then calculated a matrix of correlations for all pairwise combinations of 18 different functionaltaxonomic bryophyte and macrolichen groups and tested for average differences in correlations with elevation and disturbance history and whether particular functionaltaxonomic groups can be used to estimate the richness of other taxa. Associations between the diversities of functional-taxonomic groups within the bryophyte group and within the macrolichen group were always positive and mainly strong. Although changes in elevation and disturbance history changed the associations between the different bryophyte and macrolichen functional-taxonomic groups, we found the species richness of mosses or liverworts to be suitable for predicting overall bryophyte species richness and the species richness of green-algae macrolichens to be reliable for estimating overall macrolichen species richness. Associations between diversities of bryophyte and macrolichen groups were generally weak, suggesting that the two groups have different ecological requirements and do not share the same environmental drivers. The fact that no single bryophyte taxon can be used to predict the richness of any macrolichen group, and vice versa, points to the need to study both bryophytes and lichens. However, we found indicator taxa that are relatively easy to monitor and therefore could be used to estimate the wider biodiversity.

KEYWORDS. Biodiversity indicators, bryophyte life strategy, elevation, endemic species, disturbance, functional-taxonomic group, lichen growth form, liverwort, moss, photobiont.

The Madeira Archipelago is an important biodiversity hotspot. In particular, its main forest formation, the laurel forest (Laurisilva) has a high conservation value because of its unique biodiversity and many endemic species. This priority habitat of the European Habitats 
Directive (Annex I; 92/43/EEC) covers approximately 20\% (15,000 ha) of Madeira, mostly in the humid zone on the north coast between 300 and $1450 \mathrm{~m}$ a.s.1. Bryophytes and lichens are important components of the biodiversity in the laurel forest, where they grow on soil, rocks and the bark of trees (Boch et al. 2019a; Ruas et al. 2015; Sim-Sim et al. 2011). Besides hosting many widely distributed bryophyte and lichen species, the Madeiran laurel forest harbors numerous Macaronesian endemic bryophyte species (Sim-Sim et al. 2014).

Elevational gradients have been widely used in a space-for-time substitution approach to investigate the effects of climate change on biodiversity (Payne et al. 2017), with lower elevations representing projected higher temperatures and less precipitation in mountainous areas in the case of Madeira (Gomes et al. 2015). Results from such studies suggest that altered environmental conditions under climate change pose a threat to future bryophyte and lichen diversity on Madeira Island: while bryophyte species richness shows a mid-elevation peak, macrolichen (i.e., a commonly distinguished functional lichen group comprising foliose and fruticose growth forms, but excluding crustose species; Padgett \& Wiersma 2020) species richness increases linearly with elevation in the Madeiran laurel forest. In particular, species dependent on high humidity and the conditions of the laurel forest (e.g., endemic bryophytes) might suffer from the projected changes (Boch et al. 2019a; Patiño et al. 2016).

In addition, disturbances which are important drivers of ecosystem dynamics, and thereby modulate the structure of forests (Bengtsson et al. 2000), might pose another major threat to bryophyte and lichen diversity. In the Madeiran laurel forest, legacy effects of former disturbances, such as forestry, agriculture and grazing activities, are still visible within the protected area, significantly lowering bryophyte and macrolichen species richness, including the richness of endemic bryophytes (Boch et al. 2019a). This points to the conservation value of undisturbed old-growth forests for the conservation of overall species richness and endemics in particular. The high sensitivity against disturbances further highlights bryophytes 
and lichens as useful indicators to study the effects of environmental changes (Boch et al. 2018; Gignac 2001; Lloret \& González-Mancebo 2011; Smith et al. 2020).

In addition to using single species or the diversity of a taxonomic group as indicators for environmental conditions and changes (Patiño et al. 2018), the diversity of a group can be used to estimate the overall diversity of other taxa if they are correlated with each other under particular conditions (Oliver \& Beattie 1996; Manning et al. 2015; Prendergast et al. 1993; Wolters et al. 2006). These biodiversity relationships have various causes and can be positive, neutral or negative. Positive relationships are common when one group supports the diversity of another (e.g., ecological interdependence in specialized interactions: resource specialization hypothesis; Hutchinson 1959) or when two or more groups have similar ecological requirements and shared environmental drivers (Müller et al. 2019; Qian \& Ricklefs 2008; Wolters et al. 2006). More general interactions typically generate neutral or weak correlations (e.g., Weiner et al. 2014), while negative relationships often reflect asymmetric competitive interactions (Löbel et al. 2006) or opposing ecological requirements. Regarding the relationships between bryophyte and lichen diversity, positive associations are often assumed because of shared environmental drivers (Löbel et al. 2006). However, the associations between bryophytes and lichens have only rarely been studied, even though understanding associations between different bryophyte and lichen functional-taxonomic groups might be of particular importance in practical conservation biology. As the sampling of species richness is expensive and time consuming, identifying indicator taxa which are easy to monitor could be useful in estimating wider biodiversity (Andelman \& Fagan 2000; Bergamini et al. 2005; Howard et al. 1998; Morelli et al. 2017; Schulze et al. 2004), e.g., the diversities of taxa that are difficult to monitor. The use of suitable indicator taxa might therefore be a cost-effective alternative method to estimate the overall diversity of a species group (Bergamini et al. 2005; Kessler et al. 2011), which in turn can be used in the assessment of management actions and conservation planning, such as the selection of 
conservation areas (Andelman \& Fagan 2000; Schulze et al. 2004). However, this would require that the diversity relationships between taxa are consistent along environmental gradients (e.g., Larsen et al. 2012; Sauberer et al. 2004), which has only been tested for a few taxa (Beck et al. 2013; Dreyer et al. 2008; Gossner et al. 2014; Pharo et al. 1999; Schulze et al. 2004) and not for bryophytes and lichens (but see Bergamini et al. 2005). In particular, it remains unknown whether the associations between the diversities of different bryophyte and lichen functional-taxonomic groups change along elevational gradients and between disturbed and undisturbed areas.

To help fill this knowledge gap, we investigated the richness of various bryophyte and macrolichen functional-taxonomic groups in disturbed and undisturbed stands along a laurel forest to tree-heath forest elevational gradient on Madeira Island.

Our main research questions were:

(1) Do the associations between the diversities of different functional-taxonomic bryophyte and macrolichen groups change along the elevational gradient and differ between disturbed and undisturbed stands?

(2) Which functional-taxonomic bryophyte and macrolichen groups can be used to estimate the richness of other taxa?

\section{MeTHODS}

Study area. Madeira Island belongs to the Archipelago of Madeira (Portugal), which is situated approximately $600 \mathrm{~km}$ northwest of the Western African coast in the Atlantic Ocean. As Madeira forms a natural barrier for trade winds from the northeast which transport humid maritime air, condensation effects lead to a fog cover over the northern slopes of the island lasting approx. 200 days per year. These slopes therefore receive a high annual precipitation of up to $3000 \mathrm{~mm}$ (Prada et al. 2009), allowing the growth of the unique Mediterranean laurel and stink-laurel forest communities (Semele androgynae-Apollonio 
barbujanae and Clethro arboreae-Ocoteo foetentis), of which large parts are considered primary forest on Madeira Island. Starting at elevations of 600 to $800 \mathrm{~m}$ a.s.l., the laurel forest gradually changes to tree-heath forests dominated by Erica species and Morella faya (Vaccinio padifoli-Ericetum maderincolae and Polysticho falcinelli-Erico arboreae), which grows up to $1650 \mathrm{~m}$ a.s.1. (Capelo et al. 2005).

Sampling design and plot data. We selected our study sites from the full extent of the laurel forest of Madeira (Fig. 1), including the transition zone to the tree heath forest at its upper elevational limit, from the intersection points of a 500-m grid. This resulted in a total of 639 possible central sites. In every direction (N, E, S, W) of each site, we selected four satellite sites at a distance of $100 \mathrm{~m}$. We first assessed the central site and if it was not suitable, assessed the satellite sites in ascending order $(\mathrm{N}>\mathrm{E}>\mathrm{S}>\mathrm{W})$. We discarded sites with a slope $>60^{\circ}$, which were inaccessible (e.g., steep cliffs), had a tree cover $<20 \%$ or were plantations of non-native tree species (e.g., Eucalyptus, Acacia, Pinus). We ultimately sampled 92 sites, which were evenly distributed along the elevational gradient ( 29 plots below $600 \mathrm{~m}$ a.s.1., 30 plots between 600 and $900 \mathrm{~m}$ a.s.1., and 33 plots above $900 \mathrm{~m}$ a.s.1.; Fig. 1). Between 2011 and 2013, we established a circular plot of $100 \mathrm{~m}^{2}$ (radius $5.64 \mathrm{~m}$ ) at each site. The center of each plot was permanently marked belowground with a metal pole to ensure future relocation. Within each plot, we further selected four $1 \mathrm{~m} \times 1 \mathrm{~m}$ subplots on the forest floor including substrates such as soil, litter, humus, deadwood and rocks. The first subplot was placed in the centre of the $100-\mathrm{m}^{2}$ plot, the second $5.64 \mathrm{~m}$ northwards from the plot center, and the third and fourth at $120^{\circ}$ and $240^{\circ}$, respectively, in a clock-wise direction from the second subplot and also at $5.64 \mathrm{~m}$ from the plot center. In addition, we selected two trees with a diameter at breast height $(\mathrm{DBH})$ of at least $6.4 \mathrm{~cm}$ (for details see Boch et al. 2019b; nomenclature of vascular plants follows Euro+Med 2006-2019). On the stems of each tree, we defined two rectangular subplots of $160 \mathrm{~cm} \times 10 \mathrm{~cm}$ in the directions NNW $\left(30^{\circ}\right)$ and SSE $\left(210^{\circ}\right)$. Within each subplot, we sampled all bryophyte (i.e., mosses, liverworts, 
hornworts) and macrolichen species (comprising foliose and fruticose growth forms, but excluding crustose species) from all occurring substrates. We are aware that sampling only four $1-\mathrm{m}^{2}$ subplots on the ground and two subplots on each of the two trees most likely does not represent the total species richness of a $100-\mathrm{m}^{2}$ plot. However, given the very laborious sampling required because of the high species richness, we had to limit the survey effort in favor of a larger number of replicates.

For each plot, coordinates and elevation were measured. In addition, we distinguished between disturbed $(n=65)$ and undisturbed $(n=27)$ plots based on visible signs evaluated by Susana Fontinha, a local expert of the Secretariat of the Environment and Natural Resources of Madeira Island. Although all plots were situated in the protected area of the Madeira Natural Park, we found various, and in each plot often several, still-visible human-related disturbances comprising former pastures (32 plots) or agricultural activities (19 plots), burning (41 plots) and logging (4 plots). In addition, we recorded natural disturbances such as landslides (8 plots; for details see primary data: Boch et al. 2019b).

Bryophyte and macrolichen data. For each plot, we calculated the total species richness (total number of species in all subplots), separately for bryophytes and macrolichens (for results on elevation and disturbance effects on species richness patterns and details on primary data see Boch et al. 2019a,b). We then separated bryophytes into the two functionaltaxonomic groups mosses and liverworts and calculated their species richness. As the number and frequency of hornworts was low, we did not analyze them as a separate group but included them in the analyses on total species richness. In addition, we calculated the number of species by four different bryophyte life strategies based on the BRYOTRAIT-AZO database (http://islandlab.uac.pt/software/ver.php?id=26): colonists, short-lived shuttle species, long-lived shuttle species and perennials. These groups are considered to differ in their ecological requirements and to respond differently to habitat changes such as disturbances. Colonists have a potential life-span of several years, a rather high investment in 
sexual reproduction and small spores, i.e., they are well adapted to long-distance dispersal and typically occur in ruderal habitats. Short-lived and long-lived shuttle species both produce large spores and especially long-lived shuttle species often produce large numbers of asexual diaspores. Short-lived shuttle species often grow in open spots in a range of habitats where they are dependent on small-scale disturbances. Perennials are often large pleurocarpous mosses of rather stable habitats such as forest floors (During 1979, 1992). We further calculated the number of Red List species (CR, EN, VU) and endemic bryophyte species based on Sim-Sim et al. (2014). We followed the nomenclature of Ros et al. (2007) for liverworts and hornworts, Patiño et al. (2013) for Radula carringtonii, Ros et al. (2013) for mosses, and Patiño et al. (2017) for Rhynchostegiella spp.

Furthermore, we separated macrolichens into groups based on their vegetative traits, following Stofer et al. (2006) and complemented by Smith et al. (2009). On the one hand we built two groups based on their primary photobiont (green algae or cyanobacteria), and on the other hand we formed four groups based on their growth form (foliose adpressed, foliose ascendant, fruticose erect, fruticose pendulous). For species that were only identified to the genus level, we added values which are consistent within the particular genus (e.g., cyanobacterial photobiont for all Leptogium species). These functional groups are considered to respond differently to habitat changes and prefer different habitat conditions (Stofer et al. 2006; Boch et al. 2021). We then calculated the number of species of each group per plot. We followed Clauzade \& Roux (1985) and Smith et al. (2009) for the nomenclature of macrolichens. Unfortunately, no Red List of lichen species exists for Madeira.

Data analyses. Primary data is available on EnviDat (http://doi.org/10.16904/envid at.79). All statistical tests were performed in R version 4.0.3 (R Core Team 2020). We calculated a matrix of Pearson correlations for all pairwise combinations of the 18 different functional-taxonomic bryophyte and macrolichen groups. This resulted in a total of 153 pairwise species richness correlations. We considered a correlation to be strong when $r$ values 
were $\geq 0.6$. To detect elevational effects on the associations between the species richness of the different functional-taxonomic groups, we ranked our plots into three approximately equally replicated elevation classes based on the main distribution of forest types along the elevational gradient: thermophilous, subhumid to humid Lauraceae forests at lower elevations ( $<600 \mathrm{~m}$ a.s.1., $\mathrm{n}=29$ ); mesotemperate, humid to hyperhumid Lauraceae forests at intermediate elevations (600-900 m, $\mathrm{n}=30$ ); and meso-supra temperate Lauraceae forests and hyperhumid tree-heath forests at high elevations $(>900 \mathrm{~m}, \mathrm{n}=33)$. In addition, we analyzed the effect of disturbances on the associations between the species richness of the different functional-taxonomic groups by calculating pairwise species richness correlations of two groups of plots with $(n=65)$ and without $(n=27)$ disturbances.

\section{RESULTS}

Bryophyte and macrolichen species richness. In total, we identified 198 bryophytes to the species level (108 mosses, 89 liverworts, 1 hornwort; 72 perennial species, 42 longlived shuttle species, 15 short-lived shuttle species, 68 colonist species; 23 Macaronesian endemics and 31 threatened species; Boch et al. 2019b). On average, we found 27.6 ( $\pm 1.1 \mathrm{SE})$ bryophyte species per plot (Table 1). We found 101 macrolichen species (66 contained a green-algae and 35 a cyanobacteria photobiont; 29 foliose adpressed, 41 foliose ascendant, 16 fruticose erect, 15 fruticose pendulous; Boch et al. 2019b). Mean microlichen species per plot was $9.6( \pm 0.8$ SE; Table 1)

General associations between cryptogam groups. Across our 92 plots, 52 of the 153 pairwise correlations between the richness values of the 18 different functional-taxonomic groups were strong $(r \geq 0.6)$. We found no strong negative correlations. Associations between the diversities of functional-taxonomic groups within the bryophyte and within the macrolichen groups were always positive and mainly strong (36 of 55 correlations between 11 bryophyte groups and 16 of 21 correlations between 7 macrolichen groups). Interestingly, the 
associations between the diversities of bryophyte and macrolichen groups were never strong. Moreover, the richness of Red List bryophyte species never showed a strong relationship to the richness of any bryophyte functional-taxonomic group and was generally not related to macrolichen functional-taxonomic groups. Within the bryophyte group, the richness of mosses and liverworts correlated well with the richness of most other functional-taxonomic groups ( 9 out of 10 correlations were positive and strong for mosses and 7 out of 10 for liverworts), indicating the potential of these taxa as indicators for estimating the total bryophyte richness and the richness of other taxonomic bryophyte groups (Fig. 2). However, when using the number of moss species as a predictor of the total bryophyte species richness and the richness of the other bryophyte groups, prediction intervals were rather wide (Fig. $\mathbf{3}$, Supplementary Fig. S1). In contrast, the richness of liverworts seems to be suitable to predict at least the total bryophyte species richness, as the prediction intervals of the correlation were rather narrow (Fig. 3, Supplementary Fig. S2). Within the macrolichen group, the richness of species with a green-algae photobiont correlated well with the richness of all other functional-taxonomic groups (all six correlations were positive and strong; Fig. 2) and the prediction interval for the strong relationship between the richness of green-algae macrolichens and total macrolichen species richness was rather narrow (Fig. 3). This indicates the potential of this taxon to predict the total macrolichen richness. However, despite the strong correlations, the richness of green-algae macrolichens seems not to be suitable to reliably predict the richness of the other macrolichen groups, as the prediction intervals were quite wide (Supplementary Fig. S3).

\section{Elevation and disturbance effects on the associations between cryptogam groups.}

Splitting the dataset into three elevation groups resulted in a different picture, as the number of strong correlations between the functional-taxonomic groups was higher in the lowelevation class (70 of 153) than in the intermediate (41) and high-elevation class (45). In the low-elevation class, we even found strong correlations between the diversities of bryophyte 
and macrolichen functional-taxonomic groups. However, their number strongly decreased with elevation, from 25 of the 77 relationships in the low-elevation class to one in the intermediate and none in the high-elevation class. Interestingly, the associations of the diversities of bryophyte and macrolichen functional-taxonomic groups became negative in the high-elevation class. However, the correlations were never strong (Fig. 4). The strong associations within the bryophyte group and within the macrolichen group remained largely unchanged across the three elevation classes (from low to high elevation: 34 vs. 33 vs. 34 within the bryophyte and 11 vs. 7 vs. 12 within the macrolichen group; Fig. 4). Within the bryophyte group, the association of moss richness with the richness of other groups remained qualitatively similar among the three elevation classes compared with the overall associations. Likewise, within the macrolichen group, the association of the green-algae macrolichen richness with the richness of other groups remained qualitatively similar among the three elevation classes compared with the overall associations (Fig. 4).

A history of disturbance increased the number of strong correlations between the functional-taxonomic groups ( 52 of the 153 correlations in the disturbed group and 44 in the undisturbed group; Fig. 5). As the number of strong correlations within the bryophyte group was similar in disturbed (33 of the 55 correlations) and undisturbed plots (35), this overall increase can be attributed to a larger number of strong associations within the macrolichen group (19 of the 21 in the disturbed and 9 in the undisturbed group). In particular, the associations of the richness of fruticose erect and fruticose pendulous species with the richness of other functional-taxonomic lichen groups were stronger in disturbed plots (Fig. 5).

\section{DISCUSSION}

Bryophyte and macrolichen species richness. The outstanding conservation value of the laurel forest of Madeira as a diversity hotspot of bryophytes and lichens, as well as the functionally diverse cryptogam communities and the occurrence of many endemic 
bryophytes, has been highlighted by several authors (e.g., Boch et al. 2019a; Sim-Sim et al. 2014). We only sampled macrolichens and excluded crustose species. However, as the richness of crustose lichen species is often much higher than the richness of macrolichens and the two diversities are positively correlated (e.g., Bergamini et al. 2007), we assume that the overall lichen species richness would exceed average values found in most parts of other European countries. Sampling plots with such high numbers of bryophyte and lichen species is very laborious, as many specimens need to be identified later in the laboratory. As financial resources are often limited in monitoring programmes, conservation planning and in the assessment of management actions, identifying indicator taxa which are easy to monitor and predict the richness of other taxonomic groups or the total richness, could be useful in estimating a wider biodiversity and could therefore be a cost-effective method in practical conservation biology.

Associations between and within cryptogam groups. Across all plots in our study, the associations between bryophyte and macrolichen groups were nearly always positive but were never strong, indicating that in no case can the richness of a single bryophyte taxon be used to reliably predict the richness of any macrolichen group and vice versa. These rather general relationships with weak correlations suggest that bryophytes and macrolichens do not share the same environmental drivers and have different ecological requirements. However, this result is similar to findings from other studies of different forest types of weak associations between (macro)lichen and bryophyte richness (Blasi et al. 2010; Brurrascano et al. 2018; Djupström et al. 2010). Dynesius \& Zinko (2006) even reported negative correlations between the diversities of macrolichens and mosses or liverworts in boreal forests. One reason for weak correlations between macrolichens and bryophytes might be the local differentiation of environmental conditions, such as changing light and humidity levels with elevation in the laurel forest of Madeira, leading to differences in the growth optima for the majority of bryophytes compared with those of macrolichens, as reflected by the contrasting diversity- 
elevation relationships (Boch et al. 2019a). This is in contrast to Löbel et al. (2006), who found a positive relationship between bryophyte and lichen species richness in dry grasslands in Sweden, and to Manning et al. (2015), who studied the associations between the diversities of multiple plant and animal taxa in German grasslands. Both found bryophyte species richness to be positively related to the richness of lichens, and Manning et al. (2015) additionally reported bryophyte richness to be positively correlated with the richness of several plant and animal taxa. In fact, bryophyte species richness showed the strongest relationship with the diversity of all taxa (i.e., multidiversity) under low-intensity management. However, the relationships changed along a land-use intensity gradient and were generally weakened under high land-use intensity because of biodiversity declines and the breakdown of specialized relationships under these conditions. Likewise, Dainese et al. (2017) and Rotchés-Ribalta et al. (2018) showed that the associations between the diversities of different grassland producer and consumer taxa can change under altered landscape settings. Our findings of changing associations between the different bryophyte and macrolichen functional-taxonomic groups along the elevational gradient and between disturbance histories similarly imply that the suitability of indicator taxa might change across environmental settings. This means that no general conclusion can be drawn and that indicator taxa need to be defined for each region and environmental setting to avoid using inappropriate indicators for management decisions (Andelman \& Fagan 2000; Wolters et al. 2006).

In our study of Madeira Island, the associations between the diversities of the different taxa within the bryophyte group and within the macrolichen group remained qualitatively similar along the elevational gradient. While the associations between the diversities of the different taxa within the bryophyte group also remained similar with and without disturbance, the number of strong correlations between the diversities of the different taxa within the macrolichen group increased with a history of disturbance. This was mainly because species numbers of the different functional-taxonomic macrolichen groups became more similar in 
plots with disturbances: while the mean richness of all other macrolichen groups decreased, the mean number of fruticose erect species increased slightly and the mean number of fruticose erect species remained similar (Table 1).

The species richness of Red List bryophytes was only weakly correlated with that of other bryophyte groups. The reason for this may be that the Red List bryophytes form an ecologically rather heterogeneous group and may thus occur under very different ecological conditions. Moreover, the species richness of Red List bryophytes does not follow the general hump-back relationship between elevation and species richness exhibited by many bryophyte groups (Boch et al. 2019a).

If a short-cut to quantifying total species richness of bryophytes in the Madeiran laurel forest is needed, e.g., in monitoring programs with limited funding, we recommend using either mosses or liverworts for predicting the total species richness of bryophytes. However, the species richness of liverworts and mosses showed only weak correlations with the richness of Red List species. In addition, their richness can only be used with rather large uncertainty to predict the richness of endemic species, which are of special concern in nature conservation. The prediction interval of total bryophyte species richness based on liverwort richness is narrower than that of mosses. However, liverworts are more species rich in the laurel forest of Madeira and their identification is often much more difficult than that of mosses, meaning that there is a trade-off between reducing uncertainty and reducing time for species identification. Regarding macrolichen richness, species with a green-algae photobiont, which are easy to distinguish from cyanobacteria lichens in the field, might act as indicators for the total macrolichen richness, the richness of most other functional-taxonomic macrolichen groups, and likely also the total lichen richness including crustose species (Bergamini et al. 2007).

\section{Conclusions}


The generally weak associations between bryophyte and macrolichen groups in the laurel forest of Madeira suggest that the two groups have different ecological requirements and do not share the same environmental drivers. The fact that no single bryophyte taxon can be used to predict the richness of any macrolichen group, and vice versa, points to the need to study both bryophytes and lichens. However, our findings further highlight, at least for disturbed and undisturbed stands along elevational gradients on Madeira Island, that the species richness of mosses or liverworts is suitable to estimate the overall bryophyte species richness and that the species richness of green-algae macrolichens can be used to reliably predict overall macrolichen species richness. Sampling only these taxa might therefore serve as a cost- and time-saving alternative method to estimate the wider biodiversity, which is often key in conservation planning.

\section{ACKNOWLEDGMENTS}

This work was supported by Fundação para a Ciência e Tecnologia (FCT; projects: PTDC/AGR-CFL/111241/2009 and PTDC/AGR-FOR/3427/2014, FCT/MEC (PIDDAC)). We thank the Natural Park of Madeira Island for the permission to collect plant material, Fábio Reis, Serge Gaspar Piguet, Sara Ruas, and Susana Fontinha for providing field work assistance, Carlos Lobo for providing field work assistance and identifying critical Fissidens species, and Palmira Carvalho for identifying critical lichen species. We further thank Melissa Dawes for help editing our manuscript, the editor James Lawrey as well as the two anonymous reviewers for their constructive comments and their efforts with this manuscript.

\section{Literature Cited}

Andelman, S. J. \& W. F. Fagan. 2000. Umbrellas and flagships: efficient conservation surrogates or expensive mistakes? Proceedings of the National Academy of Sciences USA 97: 5954-5959. 
Beck, J., L. Pfiffner, L. Ballesteros-Meija, T. Blick \& H. Luka. 2013. Revisiting the indicator problem: can three epigean arthropod taxa inform about each other's biodiversity? Diversity and Distributions 19: 688-699.

Bengtsson, J., S. G. Nilsson, A. Franc \& P. Menozzi. 2000. Biodiversity, disturbances, ecosystem function and management of European forests. Forest Ecology and Management 132: 39-50.

Bergamini, A., C. Scheidegger, S. Stofer, P. Carvalho, S. Davey, M. Dietrich, F. Dubs, E. Farkas, U. Groner, K. Kärkkäinen, C. Keller, L. Lökös, S. Lommi, C. Máguas, R. Mitchell, V. J. Rico, G. Aragón, A. M. Truscott, P. A. Wolseley \& A. Watt. 2005. Performance of macrolichens and lichen genera as indicators of lichen species richness and composition. Conservation Biology 19: 1051-1062.

Bergamini, A., S. Stofer, J. Bolliger \& C. Scheidegger. 2007. Evaluating macrolichens and environmental variables as predictors of the diversity of epiphytic microlichens. Lichenologist 39: 475-489.

Blasi, C., M. Marchetti, U. Chiavetta, M. Aleffi, P. Audisio, M. M. Azzella, G. Brunialti, G. Capotorti, E. del Vico, E. Lattanzi, A. M. Persiani, S. Ravera, A. Tilia \& S. Burrascano. 2010. Multi-taxon and forest structure sampling for identification of indicators and monitoring of old-growth forest. Plant Biosystems 144: 160-170.

Boch, S., E. Allan, J.-Y. Humbert, Y. Kurtogullari, M. Lessard-Therrien, J. Müller, D. Prati, N. S. Rieder, R. Arlettaz \& M. Fischer. 2018. Direct and indirect effects of land use on bryophytes in grasslands. Science of the Total Environment 644: 60-67.

Boch, S., A. Martins, S. Ruas, S. Fontinha, P. Carvalho, F. Reis, A. Bergamini \& M. SimSim. 2019a. Bryophyte and macrolichen diversity show contrasting elevation relationships and are negatively affected by disturbances in laurel forests of Madeira island. Journal of Vegetation Science 30: 1122-1133. 
Boch, S., A. Martins, S. Ruas, S. Fontinha, P. Carvalho, F. Reis, A. Bergamini \& M. SimSim. 2019b. MadCrypto - Bryophyte and macrolichen diversity in laurel forests of Madeira. EnviDat. doi: 10.16904/envidat.79.

Boch, S., H. Saiz, E. Allan, P. Schall, D. Prati, E.-D. Schulze, D. Hessenmöller, L. B. Sparrius \& M. Fischer. 2021. Direct and indirect effects of management intensity and environmental factors on the functional diversity of lichens in Central European forests. Microorganisms 9: 463.

Burrascano, S., R. B. de Andrade, Y. Paillet, P. Ódor, G. Antonini, C. Bouget, T.

Campagnaro, F. Gosselin, P. Janssen, A. M. Persiani, J. Nascimbene, F. M. Sabatini, T. Sitzia \& C. Blasi. 2018. Congruence across taxa and spatial scales: Are we asking too much of species data? Global Ecology and Biogeography 27: 980-990.

Capelo, J., M. Sequeira, R. Jardim, S. Mesquita \& J. C. Costa. 2005. The vegetation of Madeira Island (Portugal). A brief overview and excursion guide. Quercetea 7: 95122.

Clauzade, G. \& C. Roux. 1985. Likenoj de Okcidenta Europo. Bulletin de la Société Botanique du Centre-Ouest, Numero Spécial 1: 1-893.

Dainese, M., N. J. B. Isaac, G. D. Powney, R. Bommarco, E. Öckinger, M. Kuussaari, J. Pöyry, T. G. Benton, D. Gabriel, J. A. Hodgson, W. E. Kunin, R. Lindborg, S. M. Sait \& L. Marini. 2017. Landscape simplification weakens the association between terrestrial producer and consumer diversity in Europe. Global Change Biology 23: $3040-3051$.

Djupström, L. B., K. Perhans, J. Weslien, L. M. Schroeder, L. Gustafsson \& S. Wikberg. 2010. Co-variation of lichens, bryophytes, saproxylic beetles and dead wood in Swedish boreal forests. Systematics and Biodiversity 8: 247-256.

Drever, M. C., K. Aitken, A. R. Norris \& K. Martin. 2008. Woodpeckers as reliable indicators of bird richness, forest health and harvest. Biological Conservation 141: 624-634. 
During, H. J. 1979. Life strategies of bryophytes: A preliminary review. Lindbergia 5: 2-18.

During, H. J. 1992. Ecological classification of bryophytes and lichens. Pages 1-31. In: J. W.

Bates \& A. M. Farmer (eds.), Bryophytes and lichens in a changing environment. Oxford University Press, New York.

Dynesius, M. \& U. Zinko. 2006. Species richness correlations among primary producers in boreal forests. Diversity and Distributions 12: 703-713.

Euro+Med. 2006-2019. Euro+Med PlantBase - the information resource for EuroMediterranean plant diversity. Retrieved from http://ww2.bgbm.org/EuroPlusMed/

Gignac, L. D. 2001. Bryophytes as indicators of climate change. The Bryologist 104: 410420.

Gomes, A., D. Avelar, F. Duarte Santos, H. Costa \& P. Garret. 2015. Estratégia de Adaptação às Alterações Climáticas da Região Autónoma da Madeira. Funchal, Portugal: Secretaria Regional do Ambiente e Recursos Naturais.

Gossner, M., C. Fonseca, E. Pašalić, M. Türke, M. Lange \& W. Weisser. 2014. Limitations to the use of arthropods as temperate forest indicators. Biodiversity and Conservation 23: $945-962$.

Howard, P. C., P. Viskanic, T. R. B. Davenport, F. W. Kigenyi, M. Baltzer, C. J. Dickinson, J. S. Lwanga, R. A. Matthews \& A. Balmford. 1998. Complementarity and the use of indicator groups for reserve selection in Uganda. Nature 394: 472-475.

Hutchinson, G. 1959. Homage to Santa Rosalia, or why are there so many kinds of animals? American Naturalist 93: 145- 159.

Kessler, M., S. Abrahamczyk, M. Bos, D. Buchori, D. D. Putra, S. R. Gradstein, P. Hohn, J. Kluge, F. Orend, R. Pitopang, S. Saleh, C. H. Schulze, S. G. Sporn, I. SteffanDewenter, S. S. Tjitrosoedirdjo \& T. Tscharntke. 2011. Cost-effectiveness of plant and animal biodiversity indicators in tropical forest and agroforest habitats. Journal of Applied Ecology 48: 330-339. 
Larsen, F. W., J. Bladt, A. Balmford \& C. Rahbeck. 2012. Birds as biodiversity surrogates: will supplementing birds with other taxa improve effectiveness? Journal of Applied Ecology 49: 349-356.

Lloret, F. \& J. M. González-Mancebo. 2011. Elevational distribution patterns of bryophytes in the Canary Islands and vulnerability to climate change. Flora 206: 769-781.

Löbel, S., J. Dengler \& C. Hobohm. 2006. Species richness of vascular plants, bryophytes and lichens in dry grasslands: the effects of environment, landscape structure and competition. Folia Geobotanica 41: 377-393.

Manning, P., M. M. Gossner, O. Bossdorf, E. Allan, Y.-Y. Zhang, D. Prati, N. Blüthgen, S. Boch, S. Böhm, C. Börschig, N. Hölzel, K. Jung, V. H. Klaus, A. M. Klein, T. Kleinebecker, J. Krauss, M. Lange, J. Müller, E. Pašalić, S. A. Socher, M. Tschapka, M. Türke, C. N. Weiner, M. Werner, S. Gockel, A. Hemp, S. C. Renner, K. Wells, F. Buscot, E. K. V. Kalko, K. E. Linsenmair, W. W. Weisser \& M. Fischer. 2015. Grassland management intensification weakens the associations among the diversities of multiple plant and animal taxa. Ecology 96: 1492-1501.

Morelli, F., A. P. Møller, E. Nelson, Y. Benedetti, W. Liang, P. Šímová, M. Moretti \& P. Tryjanowski. 2017. The common cuckoo is an effective indicator of high bird species richness in Asia and Europe. Scientific Reports 7: 4376.

Müller, J., S. Boch, D. Prati, S. A. Socher, U. Pommer, D. Hessenmöller, P. Schall, E.-D. Schulze \& M. Fischer. 2019. Effects of forest management on bryophyte species richness in Central European forests. Forest Ecology and Management 432: 850-859.

Oliver, I. \& A. J. Beattie. 1996. Designing a cost-effective invertebrate survey: a test of methods for rapid assessment of biodiversity. Ecological Applications 6: 594-607.

Padgett, T. \& Y. F. Wiersma. 2020. Arboreal macrolichen community composition and habitat associations in boreal forested wetlands of Newfoundland, Canada. The Bryologist 123: 64-74. 
Patiño, J., N. Devos, A. Vanderpoorten, A. Schäfer-Verwimp \& M. Renner. 2013. The identity of Radula carringtonii Jack. Journal of Bryology 35: 314-316.

Patiño, J., R. G. Mateo, F. Zanatta, A. Marquet, S. C. Aranda, P. A. V. Borges, G. Dirkse, R. Gabriel, J. M. Gonzalez-Mancebo, A. Guisan, J. Muñoz, M. Sim-Sim \& A. Vanderpoorten. 2016. Climate threat on the Macaronesian endemic bryophyte flora. Scientific Reports 6: 29156.

Patiño, J., L. Hedenäs, G. Dirkse, M. Ignatov, B. Papp, F. Müller, J. M. González-Mancebo \& A. Vanderpoorten. 2017. Species delimitation in the recalcitrant moss genus Rhynchostegiella (Brachytheciaceae). Taxon 66: 293-308.

Patiño, J., C. Gómez-Rodríguez, A. Pupo-Correia, M. Sequeira \& A. Vanderpoorten. 2018. Trees as habitat islands: Temporal variation in alpha and beta diversity in epiphytic laurel forest bryophyte communities. Journal of Biogeography 45: 1727-1738.

Payne, D., E. M. Spehn, M. Snethlage \& M. Fischer. 2017. Opportunities for research on mountain biodiversity under global change. Current Opinion in Environmental Sustainability 29: 40-47.

Pharo, E. J., A. J. Beattie \& D. Binns. 1999. Vascular plant diversity as a surrogate for bryophyte and lichen diversity. Conservation Biology 13: 282-292.

Prada, S., M. M. Sequeira, C. Figueira \& M. O. Silva. 2009. Fog precipitation and rainfall interception in the natural forests of Madeira Island (Portugal). Agricultural and Forest Meteorology 149: 1179-1187.

Prendergast, J. R., R. M. Quinn, J. H. Lawton, B. C. Eversham \& D. W. Gibbons. 1993. Rare species, the coincidence of diversity hotspots and conservation strategies. Nature 365: $335-337$.

Qian, H. \& R. E. Ricklefs. 2008. Global concordance in diversity patterns of vascular plants and terrestrial vertebrates. Ecology Letters 11: 547-553. 
R Core Team. 2020. R: a language and environment for statistical computing. Vienna, Austria: R Foundation for Statistical Computing.

Ros, R. M., V. Mazimpaka, U. Abou-Salama, M. Aleffi, T. L. Blockeel, M. Brugués, M. J. Cano, R. M. Cros, M. G. Dia, G. M. Dirkse, W. El-Saadawi, A. Erdağ, A. Ganeva, J. M. González-Mancebo, I. Herrnstadt, K. Khalil, H. Kürschner, E. Lanfranco, A. Losada-Lima, M. S. Refai, S. Rodríguez-Nuñez, M. Sabovljević, C. Sérgio, H. Shabbara, M. Sim-Sim \& L. Söderström. 2007. Hepatics and Anthocerotes of the Mediterranean, an annotated checklist. Cryptogamie Bryologie 28: 351-437.

Ros, R. M., V. Mazimpaka, U. Abou-Salama, M. Aleffi, T. L. Blockeel, M. Brugués, R. M. Cros, M. G. Dia, G. M. Dirkse, I. Draper, W. El-Saadawi, A. Erdağ, A. Ganeva, R. Gabriel, J. M. González-Mancebo, C. Granger, I. Herrnstadt, V. Hugonnot, K. Khalil, H. Kürschner, A. Losada-Lima, L. Luís, S. Mifsud, M. Privitera, M. Puglisi, M. Sabovljević, C. Sérgio, H. M. Shabbara, M. Sim-Sim, A. Sotiaux, R. Tacchi, A. Vanderpoorten \& O. Werner. 2013. Mosses of the Mediterranean, an annotated checklist. Cryptogamie Bryologie 34: 99-283.

Rotchés-Ribalta, R., M. Winsa, S. P. Roberts \& E. Öckinger. 2018. Associations between plant and pollinator communities under grassland restoration respond mainly to landscape connectivity. Journal of Applied Ecology 55: 2822-2833.

Ruas, S., A. Bergamini, P. Carvalho, S. Fontinha \& M. Sim-Sim. 2015. The community structure of bryophytes and macrolichens in Madeira's natural forest: The effects of environmental variables and relations to old-growth forests. Nova Hedwigia 100: 439460.

Sauberer, N., K. P. Zulka, M. Abensperg-Traun, H.-M. Berg, G. Bieringer, N. Milasowszky, D. Moser, C. Plutzar, M. Pollheimer, C. Storch, R. Tröst, H. Zechmeister \& G. Grabherr. 2004. Surrogate taxa for biodiversity in agricultural landscapes of eastern Austria. Biological Conservation 117: 181-190. 
Schulze, C. H., M. Waltert, P. J. A. Kessler, R. Pitopang, D. Veddeler, M. Mühlenberg, R. Gradstein, C. Leuschner, I. Steffan-Dewetner \& T. Tscharnke. 2004. Biodiversity indicator groups of tropical land-use systems: comparing plants, birds and insects. Ecological Applications 14: 1321- 1333.

Sim-Sim, M., A. Bergamini, L. Luís, S. Fontinha, S. Martins, C. Lobo \& M. Stech. 2011. Epiphytic bryophyte diversity on Madeira Island: Effects of tree species on bryophyte species richness and composition. The Bryologist 114: 142-154.

Sim-Sim, M., S. Ruas, S. Fontinha, L. Hedenäs, C. Sérgio \& C. Lobo. 2014. Bryophyte conservation on a North Atlantic hotspot: threatened bryophytes in Madeira and Selvagens Archipelagos (Portugal). Systematics and Biodiversity 12: 315-330.

Smith, C. W., A. Aptroot, B. J. Coppins, A. Fletcher, O. L. Gilbert, P. W. James \& P. A. Wolseley. 2009. The Lichens of Great Britain and Ireland. British Lichen Society, London.

Smith, R. J., S. Jovan, D. Stanton \& S. Will-Wolf. 2020. Epiphytic macrolichen communities indicate climate and air quality in the U.S. Midwest. The Bryologist 123: 517-533.

Stofer, S., A. Bergamini, G. Aragón, P. Carvalho, B. J. Coppins, S. Davey, M. Dietrich, E. Farkas, K. Kärkkäinen, C. Keller, L. Lökös, S. Lommi, C. Máguas, R. Mitchell, P. Pinho, V. J. Rico, A.-M. Truscott, P. A. Wolseley, A. Watt \& C. Scheidegger. 2006. Species richness of lichen functional groups in relation to land use intensity. Lichenologist 38: 331-353.

Weiner, C. N., M. Werner, K. E. Linsenmair \& N. Blüthgen. 2014. Land-use impacts on plant-pollinator networks: interaction strength and specialization predict pollinator declines. Ecology 95: 466-474.

Wolters, V., J. Bengtsson \& A. Zaitsev. 2006. Relationships among the species richness of different taxa. Ecology 87: 1886-1895. 
manuscript received January 28, 2021; accepted March 1, 2021.

\section{Supplementary documents online:}

Supplementary Figure S1. Relationships between the species richness of different bryophyte groups and the species richness of mosses.

Supplementary Figure S2. Relationships between the species richness of different bryophyte groups and the species richness of liverworts.

Supplementary Figure S3. Relationships between the species richness of different macrolichen groups and the species richness of green-algae macrolichens. 


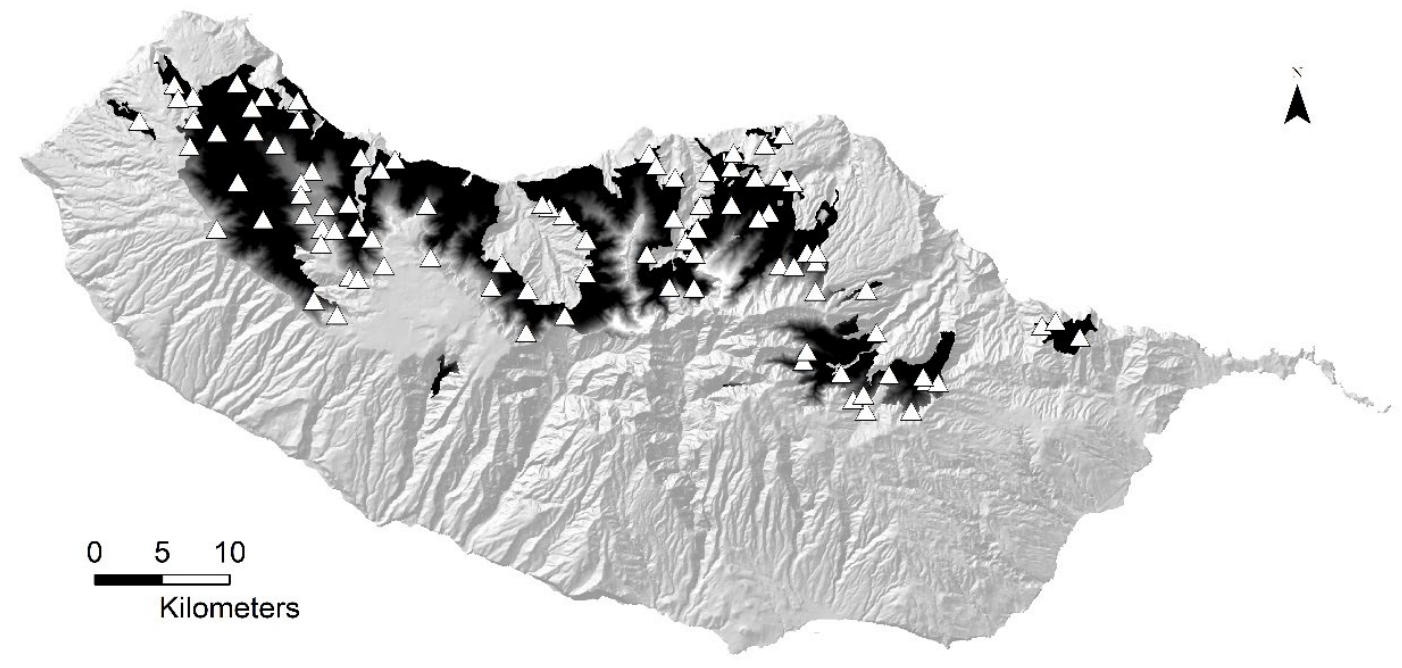

Figure 1. Location of the 92 plots (white triangles) distributed along the elevational gradient from the laurel forest to the tree-heath forest (black area) on Madeira Island. 


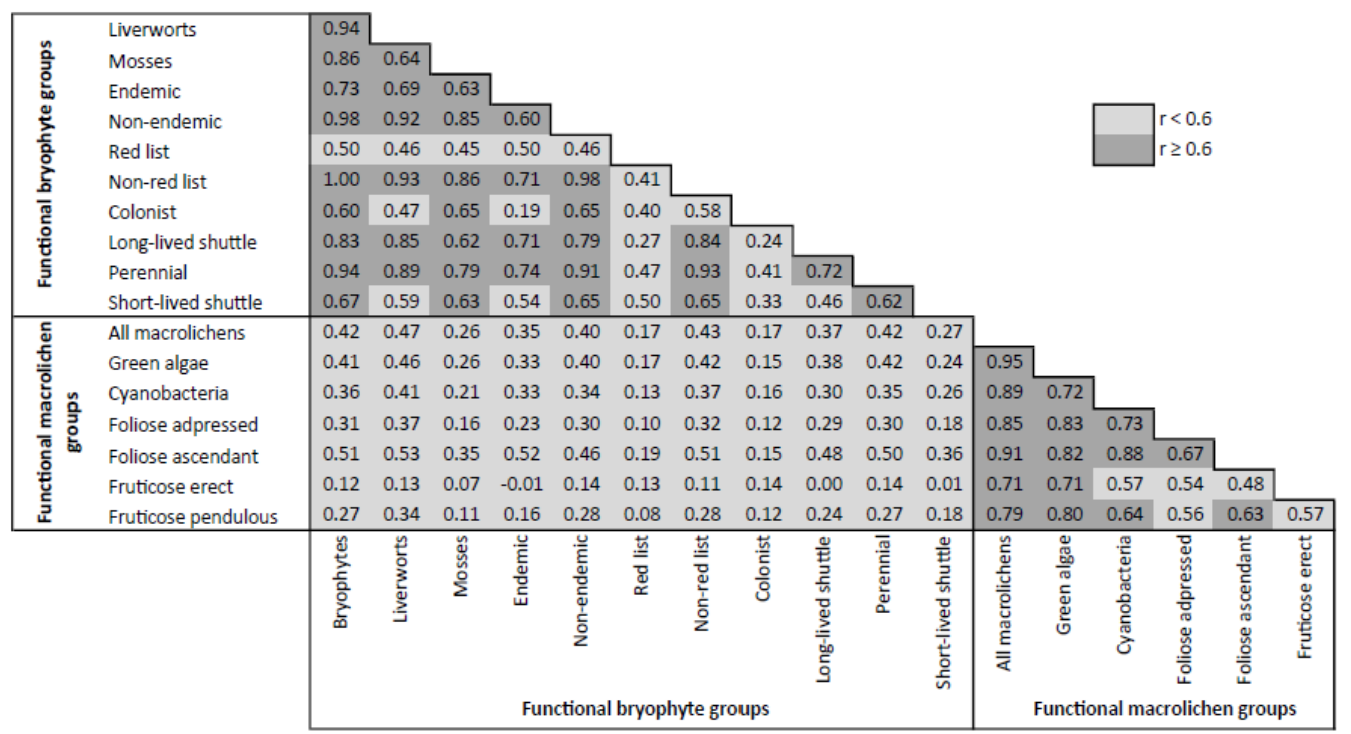

Figure 2. General associations between the species richness of different bryophyte and macrolichen functional-taxonomic groups on Madeira Island. 

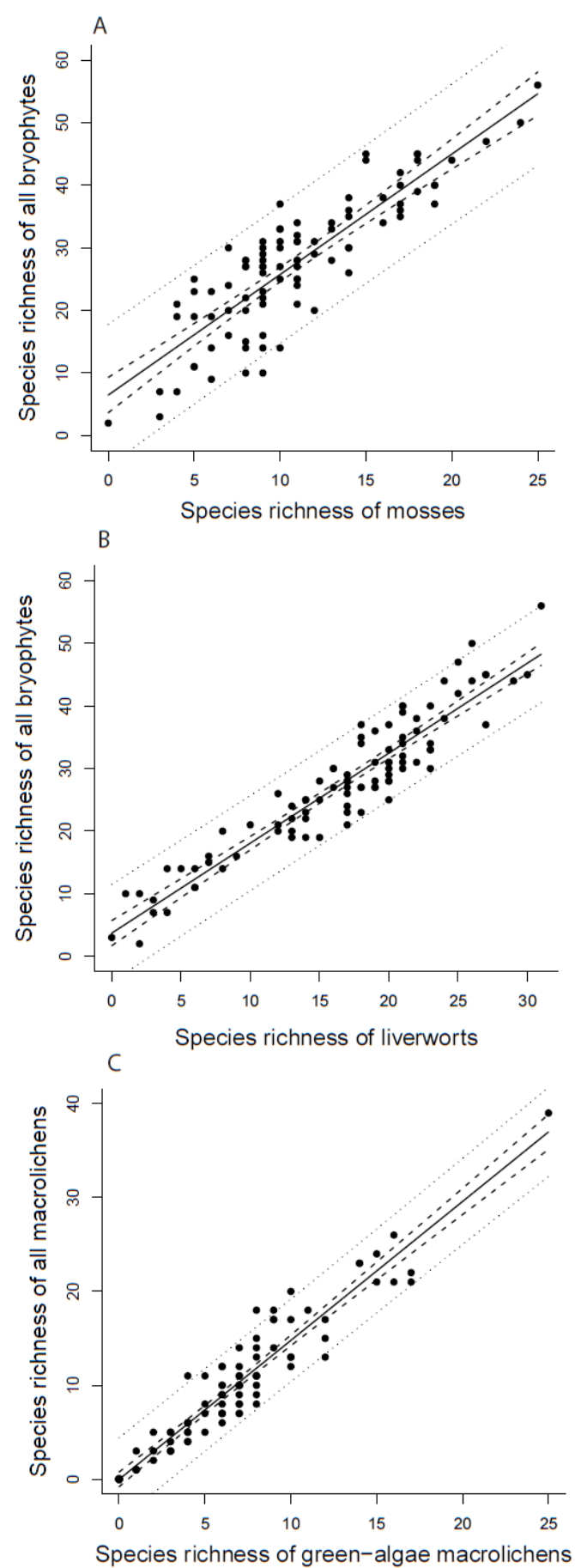

Figure 3. A. Predictions of total bryophyte species richness by means of mosses. B.

Predictions of total bryophyte species richness by means of liverworts. C. Prediction of species richness of macrolichens by means of species richness of green-algae macrolichens. Solid lines indicate significant relationships from linear regressions (all significant at $p$ $<0.001$ ), dashed lines indicate the $95 \%$ confidence interval, and dotted lines indicate the $95 \%$ prediction interval. 
A) Elevation $<600 m(n=29)$

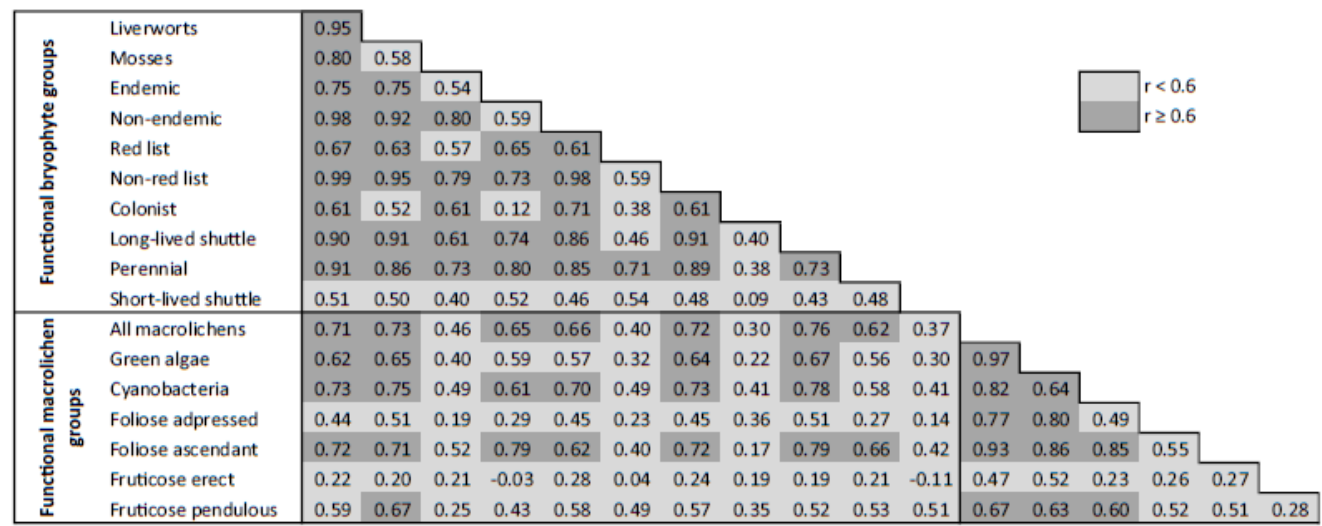

B) Elevation $600-900 \mathrm{~m}(\mathrm{n}=30)$

\begin{tabular}{|c|c|c|c|c|c|c|c|c|c|c|c|c|c|c|c|c|c|c|}
\hline \multirow{10}{*}{ 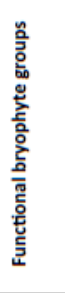 } & Liverworts & 0.92 & & & & & & & & & & & & & & & & \\
\hline & Mosses & 0.88 & 0.64 & & & & & & & & & & & & & & & \\
\hline & Endemic & 0.59 & 0.46 & 0.63 & & & & & & & & & & & & & & \\
\hline & Non-endemic & 0.98 & 0.93 & 0.84 & 0.42 & & & & & & & & & & & & & \\
\hline & Red list & 0.57 & 0.53 & 0.50 & 0.43 & 0.54 & & & & & & & & & & & & \\
\hline & Non-red list & 0.99 & 0.92 & 0.88 & 0.58 & 0.98 & 0.48 & & & & & & & & & & & \\
\hline & Colonist & 0.67 & 0.51 & 0.71 & 0.12 & 0.72 & 0.49 & 0.65 & & & & & & & & & & \\
\hline & Long-tived shuttle & 0.72 & 0.72 & 0.56 & 0.47 & 0.69 & 0.15 & 0.75 & 0.18 & & & & & & & & & \\
\hline & Perennial & 0.94 & 0.90 & 0.78 & 0.67 & 0.89 & 0.58 & 0.92 & 0.46 & 0.62 & & & & & & & & \\
\hline & Short-lived shuttle & 0.79 & 0.69 & 0.75 & 0.58 & 0.75 & 0.53 & 0.78 & 0.47 & 0.49 & 0.73 & & & & & & & \\
\hline \multirow{7}{*}{ 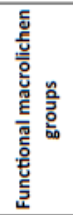 } & All macrolichens & 0.56 & 0.43 & 0.61 & 0.48 & 0.52 & 0.12 & 0.59 & 0.28 & 0.52 & 0.50 & 0.55 & & & & & & \\
\hline & Green algae & 0.55 & 0.46 & 0.54 & 0.37 & 0.52 & 0.25 & 0.55 & 0.30 & 0.57 & 0.46 & 0.44 & 0.89 & & & & & \\
\hline & Cyanobacteria & 0.40 & 0.25 & 0.50 & 0.46 & 0.34 & -0.10 & 0.44 & 0.16 & 0.29 & 0.39 & 0.50 & 0.81 & 0.45 & & & & \\
\hline & Foliose adpressed & 0.45 & 0.36 & 0.46 & 0.35 & 0.42 & 0.11 & 0.47 & 0.23 & 0.28 & 0.47 & 0.41 & 0.68 & 0.66 & 0.49 & & & \\
\hline & Foliose ascendant & 0.50 & 0.34 & 0.58 & 0.55 & 0.42 & 0.13 & 0.51 & 0.20 & 0.45 & 0.46 & 0.55 & 0.94 & 0.78 & 0.83 & 0.49 & & \\
\hline & Fruticose erect & 0.20 & 0.18 & 0.19 & 0.09 & 0.21 & 0.05 & 0.21 & 0.25 & 0.28 & 0.07 & 0.15 & 0.46 & 0.46 & 0.30 & 0.09 & 0.37 & \\
\hline & Fruticose pendulous & 0.05 & 0.14 & -0.08 & -0.13 & 0.08 & -0.17 & 0.07 & -0.07 & 0.36 & -0.03 & -0.06 & 0.18 & 0.19 & 0.10 & -0.32 & 0.13 & 0.23 \\
\hline
\end{tabular}

C) Elevation $>900 m(n=33)$

\begin{tabular}{|c|c|c|c|c|c|c|c|c|c|c|c|c|c|c|c|c|c|c|}
\hline \multirow{10}{*}{ 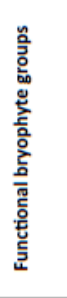 } & Liverworts & 0.92 & & & & & & & & & & & & & & & & \\
\hline & Mosses & 0.95 & 0.74 & & & & & & & & & & & & & & & \\
\hline & Endemic & 0.77 & 0.75 & 0.70 & & & & & & & & & & & & & & \\
\hline & Non-endemic & 0.99 & 0.90 & 0.94 & 0.65 & & & & & & & & & & & & & \\
\hline & Red list & 0.32 & 0.26 & 0.34 & 0.35 & 0.29 & & & & & & & & & & & & \\
\hline & Non-red list & 1.00 & 0.92 & 0.94 & 0.75 & 0.98 & 0.22 & & & & & & & & & & & \\
\hline & Colonist & 0.69 & 0.61 & 0.67 & 0.35 & 0.72 & 0.33 & 0.67 & & & & & & & & & & \\
\hline & Long-lived shuttle & 0.77 & 0.76 & 0.68 & 0.78 & 0.71 & 0.13 & 0.77 & 0.17 & & & & & & & & & \\
\hline & Perennial & 0.93 & 0.83 & 0.90 & 0.71 & 0.92 & 0.21 & 0.94 & 0.53 & 0.68 & & & & & & & & \\
\hline & Short-lived shuttle & 0.58 & 0.53 & 0.56 & 0.43 & 0.58 & 0.51 & 0.55 & 0.38 & 0.35 & 0.47 & & & & & & & \\
\hline \multirow{8}{*}{ 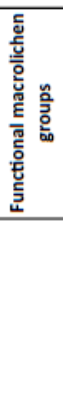 } & All macrolichens & -0.04 & 0.06 & -0.11 & 0.04 & -0.05 & 0.21 & -0.06 & 0.12 & 0.03 & -0.15 & -0.16 & & & & & & \\
\hline & Green algae & -0.05 & -0.01 & -0.07 & 0.00 & -0.05 & 0.14 & -0.06 & 0.07 & 0.00 & -0.11 & -0.14 & 0.92 & & & & & \\
\hline & Cyanobacteria & -0.01 & 0.16 & -0.15 & 0.10 & -0.04 & 0.26 & -0.04 & 0.16 & 0.06 & -0.17 & -0.13 & 0.81 & 0.52 & & & & \\
\hline & Foliose adpressed & -0.15 & -0.06 & -0.20 & -0.04 & -0.16 & 0.05 & -0.16 & -0.03 & -0.01 & -0.24 & -0.20 & 0.84 & 0.78 & 0.68 & & & \\
\hline & Foliose ascendant & 0.12 & 0.26 & -0.02 & 0.26 & 0.07 & 0.20 & 0.10 & 0.14 & 0.22 & 0.00 & -0.05 & 0.81 & 0.63 & 0.83 & 0.54 & & \\
\hline & Fruticose erect & -0.15 & -0.18 & -0.11 & -0.22 & -0.12 & 0.34 & -0.19 & 0.16 & -0.27 & -0.18 & -0.21 & 0.60 & 0.65 & 0.34 & 0.47 & 0.17 & \\
\hline & Fruticose pendulous & 0.03 & 0.07 & -0.01 & 0.01 & 0.03 & 0.08 & 0.02 & 0.16 & -0.01 & -0.06 & -0.01 & 0.78 & 0.82 & 0.47 & 0.52 & 0.54 & 0.39 \\
\hline & & 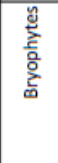 & 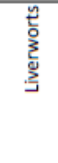 & 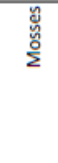 & $\begin{array}{l}\text { 亗 } \\
\text { हूँّ } \\
\text { 己. }\end{array}$ & 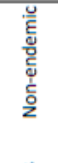 & 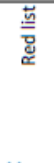 & 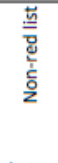 & $\begin{array}{l} \\
\frac{\mathrm{n}}{\mathrm{c}} \\
\frac{\mathrm{o}}{\mathrm{g}}\end{array}$ & 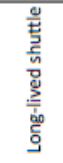 & 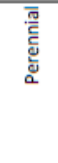 & 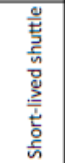 & 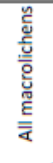 & 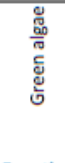 & 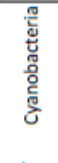 & 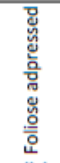 & 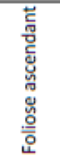 & 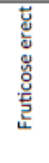 \\
\hline
\end{tabular}

Figure 4. Changing associations between the species richness of different bryophyte and

lichen functional-taxonomic groups among the three elevation classes on Madeira Island. A.

Low $(<600 \mathrm{~m} ; \mathrm{n}=29)$. B. Intermediate $(600-900 \mathrm{~m} ; \mathrm{n}=30)$. C. High $(>900 \mathrm{~m} ; \mathrm{n}=33)$. 


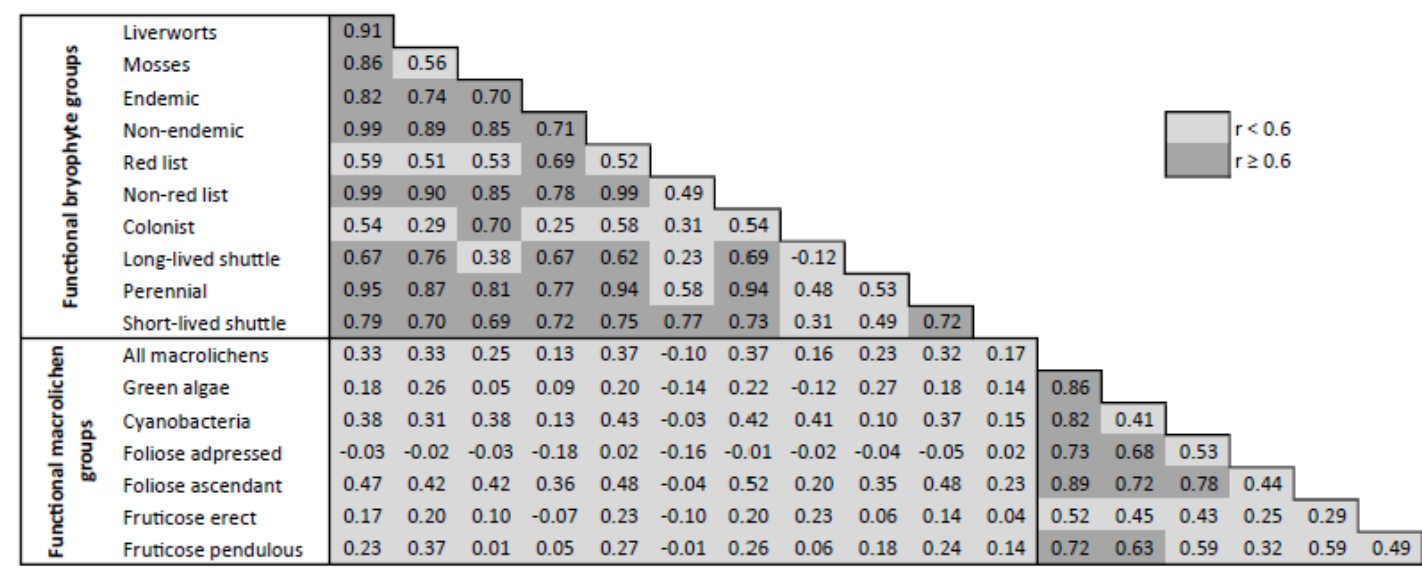

B) With disturbances $(n=65)$

\begin{tabular}{|c|c|c|c|c|c|c|c|c|c|c|c|c|c|c|c|c|c|c|}
\hline \multirow{10}{*}{ 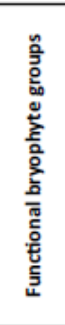 } & Liverworts & 0.94 & & & & & & & & & & & & & & & & \\
\hline & Mosses & 0.87 & 0.66 & & & & & & & & & & & & & & & \\
\hline & Endemic & 0.68 & 0.62 & 0.62 & & & & & & & & & & & & & & \\
\hline & Non-endemic & 0.99 & 0.93 & 0.85 & 0.55 & & & & & & & & & & & & & \\
\hline & Red list & 0.46 & 0.44 & 0.39 & 0.42 & 0.43 & & & & & & & & & & & & \\
\hline & Non-red list & 1.00 & 0.94 & 0.87 & 0.66 & 0.98 & 0.37 & & & & & & & & & & & \\
\hline & Colonist & 0.61 & 0.50 & 0.63 & 0.11 & 0.66 & 0.43 & 0.59 & & & & & & & & & & \\
\hline & Long-lived shuttle & 0.87 & 0.87 & 0.69 & 0.72 & 0.83 & 0.27 & 0.88 & 0.31 & & & & & & & & & \\
\hline & Perennial & 0.92 & 0.88 & 0.78 & 0.70 & 0.90 & 0.42 & 0.92 & 0.37 & 0.76 & & & & & & & & \\
\hline & Short-lived shuttle & 0.61 & 0.53 & 0.59 & 0.36 & 0.61 & 0.30 & 0.60 & 0.33 & 0.43 & 0.55 & & & & & & & \\
\hline \multirow{9}{*}{ 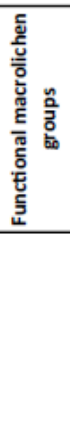 } & All macrolichens & 0.42 & 0.47 & 0.25 & 0.38 & 0.39 & 0.23 & 0.41 & 0.15 & 0.38 & 0.42 & 0.29 & & & & & & \\
\hline & Green algae & 0.44 & 0.48 & 0.30 & 0.36 & 0.42 & 0.25 & 0.43 & 0.18 & 0.38 & 0.45 & 0.26 & 0.97 & & & & & \\
\hline & Cyanobacteria & 0.32 & 0.41 & 0.13 & 0.35 & 0.29 & 0.18 & 0.32 & 0.08 & 0.32 & 0.32 & 0.29 & 0.91 & 0.78 & & & & \\
\hline & Foliose adpressed & 0.36 & 0.43 & 0.18 & 0.29 & 0.35 & 0.17 & 0.36 & 0.13 & 0.34 & 0.36 & 0.21 & 0.87 & 0.86 & 0.77 & & & \\
\hline & Foliose ascendant & 0.47 & 0.51 & 0.31 & 0.50 & 0.42 & 0.25 & 0.46 & 0.10 & 0.48 & 0.46 & 0.38 & 0.92 & 0.84 & 0.91 & 0.71 & & \\
\hline & Fruticose erect & 0.16 & 0.18 & 0.09 & 0.09 & 0.16 & 0.22 & 0.14 & 0.15 & 0.02 & 0.19 & 0.05 & 0.77 & 0.78 & 0.65 & 0.63 & 0.58 & \\
\hline & Fruticose pendulous & 0.30 & 0.36 & 0.14 & 0.22 & 0.29 & 0.11 & 0.30 & 0.13 & 0.26 & 0.29 & 0.21 & 0.81 & 0.83 & 0.67 & 0.62 & 0.67 & 0.58 \\
\hline & & 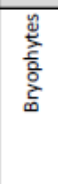 & 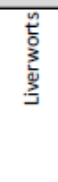 & 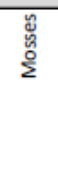 & 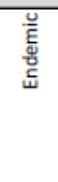 & 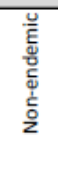 & 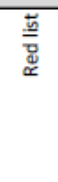 & 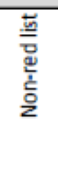 & $\begin{array}{l}\frac{5}{5} \\
\frac{0}{0}\end{array}$ & 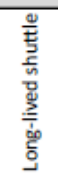 & 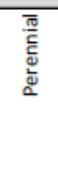 & 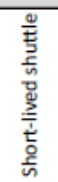 & 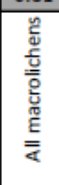 & 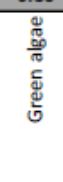 & 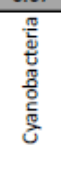 & 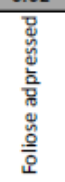 & 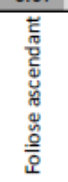 & 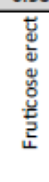 \\
\hline & & \multicolumn{11}{|c|}{ Functional bryophyte groups } & \multicolumn{6}{|c|}{ Functional macrolichen groups } \\
\hline
\end{tabular}

Figure 5. Changing associations between the species richness of different bryophyte and lichen functional-taxonomic groups on Madeira Island. A. Between undisturbed plots ( $\mathrm{n}=$ 27). B. Between disturbed plots $(n=65)$. 